\title{
Topossequência de solos na transição Campos Naturais-Floresta na região de Humaitá, Amazonas'
}

\author{
Milton César Costa CAMPOS², Mateus Rosas RIBEIRO3, Valdomiro Severino de Souza JÚNIOR ${ }^{4}$, Mateus \\ Rosas Ribeiro FILHO ${ }^{4}$, Maria Conceição ALMEIDA ${ }^{5}$
}

\section{RESUMO}

O objetivo deste trabalho foi estudar as relaçôes solo-relevo em uma topossequência de transição campo/floresta na região de Humaitá, AM. A área do estudo foi selecionada com base na representatividade regional e no grau de preservação do ambiente. $\mathrm{O}$ estudo foi realizado ao longo de um caminhamento que atravessou os diferentes pedoambientes, partindo do ambiente de campo natural até o ambiente de floresta. Esses pedoambientes foram identificados e delimitados conforme a curvatura do terreno, expressão dos padróes vegetacionais e características pedológicas. Foram abertas trincheiras nos diversos segmentos e os perfis foram caracterizados morfologicamente e coletados por horizonte. Foram realizadas análises físicas e químicas para caracterização e determinados $\mathrm{SiO}_{2}, \mathrm{Al}_{2} \mathrm{O}_{3}$ e $\mathrm{Fe}_{2} \mathrm{O}_{3}$ por ataque sulfúrico, óxidos de Fe "livres" com ditionito-citrato-bicarbonato e o ferro mal cristalizado com oxalato de amônio. Análises mineralógicas foram realizadas por difratometria de raios X. Os resultados sugerem que a variação dos solos na topossequência tem relação direta com a variação do relevo, que condiciona a drenagem e o nível do lençol freático.

PALAVRAS-CHAVE: pedogênese, relaçóes solo-paisagem, classificação do solo.

\section{Soil-relief relationships in a grassland/forest transition in the region of Humaitá, Amazonas State, Brazil}

\section{ABSTRACT}

The objective of this work was to study soil-relief relations in a grassland-forest transition, in the region of Humaitá, Amazonas State, Brazil. The study area was selected based on the criterion of regional representativity (most common landscape) and in the level of environmental preservation. The sample collection was carried out in a transect from the grassland towards the forest, and the different soil environments were identified and limited according relief position, vegetation patterns and soil characteristics. Soil profiles were morphologically characterized and samples collected from all horizons for physical and chemical analysis for normal profile characterization. including $\mathrm{SiO}_{2}, \mathrm{Al}_{2} \mathrm{O}_{3}$ and $\mathrm{Fe}_{2} \mathrm{O}_{3}$ extracted by $\mathrm{H}_{2} \mathrm{SO}_{4}$ attack, free iron oxides by DCB extraction and poor crystalline iron oxides extracted by ammonium oxalate. Mineralogical analysis was also carried out by X-ray diffraction. The results suggest that soil variation in the landscape was directly related with the relief, which determines soil drainage and water table level.

KEYWORDS: soil genesis, soil-landscape relations, soil classification

\footnotetext{
1 Parte da Tese Doutorado do primeiro autor, apresentada ao Programa de Pós-Graduação em Ciências do Solo, Universidade Federal Rural de Pernambuco - UFRPE.

2 Professor Adjunto do Instituto de Educação, Agricultura e Ambiente, Universidade Federal do Amazonas. Rua 29 de Agosto, 786, Centro, CEP.: 69.800-000, Humaitá-AM. E-mail: agromccc@yahoo.com.br; mcesarsolos@ufam.edu.br

${ }^{3}$ Professor Associado do Departamento de Agronomia, Universidade Federal Rural de Pernambuco. Rua Dom Manoel de Medeiros, s/n, Dois Irmãos - CEP: 52171-900 - Recife/PE. Bolsista do CNPq. E-mail: mrosas@depa.ufrpe.br

${ }_{4}^{4}$ Professores do Departamento de Agronomia, Universidade Federal Rural de Pernambuco. Rua Dom Manoel de Medeiros, s/n, Dois Irmãos - CEP: 52171-900 - Recife/PE. E-mail: vsouzajr@yahoo.com; mateusrf@depa.ufrpe.br

${ }^{5}$ Doutoranda do Programa de Pós-Graduação em Ciências do Solo, Universidade Federal Rural de Pernambuco. Rua Dom Manoel de Medeiros, s/n, Dois Irmãos - CEP: $52171-900$ - Recife/PE. E-mail: marycalmeida@yahoo.com.br
} 


\section{INTRODUÇÃO}

As relaçóes entre solos, relevo e vegetação caracterizam-se por serem interdependentes. Se as condiçôes de drenagem e a variação dos solos interferem nas formaçôes vegetais, por outro lado, as condiçóes de relevo influenciam em várias propriedades dos solos, como estrutura, porosidade, densidade do solo e teor de nutrientes. Segundo Jafari et al. (2003) estas relaçôes são governadas pelas características topográficas do terreno, que têm papel determinante na formação e distribuição da vegetação, pois a topografia condiciona diferenças no regime hídrico, favorecendo solos mais ou menos desenvolvidos, implicando dessa maneira em maior ou menor capacidade de suporte à vegetação.

Para Campos et al. (2007) a topografia tem sido frequentemente relatada como sendo causa de variaçôes nos atributos do solo que se refletem na vegetação. Estudos desenvolvido por Botrel et al. (2002) em uma sequência Neossolo-Cambissolo-Argissolo em área de floresta estacional semidecidual revelou um declínio na disponibilidade de água e de nutrientes com as mudanças do relevo. El-Ghani e Amer (2003) destacaram que as variaçóes na fertilidade dos solos em ecossistemas naturais são oriundas das configuraçôes do relevo, bem como do próprio regime de umidade do solo.

A região amazônica apresenta grande diversidade de solos e paisagens, o que justifica estudos dessa natureza. Dentre estas paisagens, inclui-se os chamados Campos Naturais de Humaitá, que compreendem as áreas dos "campos de Puciari - Humaitá". Este tipo de paisagem inclui várias formaçōes campestres abertas, onde se alternam, pequenas árvores isoladas e florestas de galerias ao longo dos igarapés (Braun e Ramos 1959).

De acordo com Freitas et al. (2002) esses campos formam mosaicos com as florestas circundantes, sendo o contato entre essas vegetaçôes, em alguns locais, abrupto, enquanto em outros a transição entre a floresta e o campo natural apresentase gradual. Para Martins et al. (2006a) e Vidotto et al. (2007), que investigaram os atributos do solo em ambientes de campos naturais e florestas na região Sul do Amazonas essas relaçóes são marcantes. Dessa forma o objetivo deste trabalho foi investigar as relaçóes solo-relevo em uma transição campo/floresta na região de Humaitá, Estado do Amazonas.

\section{MATERIAL E MÉTODOS}

\section{Caracterização das áreas estudadas}

A área de estudo localiza-se na região de Humaitá, sul do Estado do Amazonas, situada nas coordenadas geográficas de 7o 30' 24" S e 630 04'56" W. A regiáo apresenta relevo aproximado ao do tipo "tabuleiro", com desníveis muito pequenos e bordos ligeiramente abaulados. Esses terraços fluviais antigos constituem os divisores de água entre os pequenos igarapés da região. O desnível dessas zonas tabulares em relação aos igarapés é da ordem de 15 a 29 metros, ocorrendo, entretanto, de maneira abrupta (Braun e Ramos 1959).

A geologia da área estudada é formada por aluviōes antigos indiferenciados referidos ao Holoceno. Os sedimentos desta formação são advindos de dois ciclos de sedimentação: a) bancos arenosos, inferiores, que representam a sedimentaçáo plúvio-fluvial e b) sedimentos argilosos superiores, indicando sedimentaçáo lacustre (Braun e Ramos 1959). A região compreende uma vegetaçáo de contato entre campos e florestas, que se caracteriza por áreas que incluem varias formaçôes campestres, onde a vegetação que prevalece é a gramíneo-lenhosa baixa, alternada com pequenas árvores isoladas e floresta de galerias ao longo dos rios (Braun e Ramos 1959).

O clima da região, segundo a classificação de Köppen, é do tipo Am, tropical chuvoso (chuvas do tipo monção), apresentando um período seco de pequena duraçáo, com temperaturas variando entre 25 e $27^{\circ} \mathrm{C}$ e precipitação média anual de $2.500 \mathrm{~mm}$, com período chuvoso iniciando em outubro e prolongando-se até junho, e umidade relativa do ar entre 85 e $90 \%$.

\section{Métodos de campo, laboratório e escritório}

Após a seleção de uma topossequência representativa dos vários ambientes de ocorrência, foi estabelecido um caminhamento, partindo do ambiente de campo natural até o ambiente de floresta (Figura 1). O transecto atravessou os diferentes pedoambientes existentes, os quais foram identificados e delimitados conforme a curvatura do terreno, expressão dos padrōes vegetacionais e características pedológicas.

Foram abertas trincheiras em cada pedoambiente da topossequência para caracterização morfológica, física, química e mineralógica dos solos. A identificação dos horizontes e a descrição morfológica foram realizadas conforme Santos et al. (2005), com coleta de amostras em todos os horizontes. Os solos foram classificados segundo critérios estabelecidos por SiBCS (Embrapa 2006).

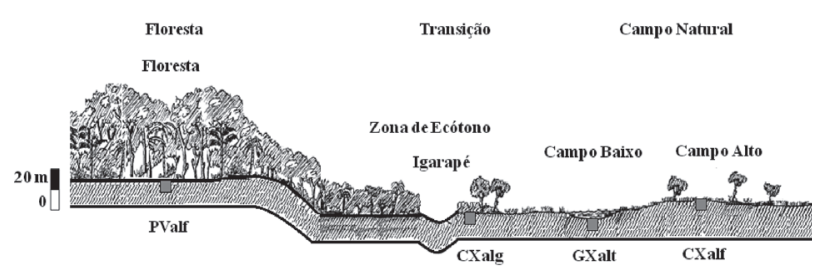

Figura1-Perfilesquemáticomostrando avegetação, relevo eas classes de solos em umatopossequênciatípica datransição campos/lloresta na região de Humaitá, AM. Fonte: Adaptado de Braun e Ramos (1959). 
A análise granulométrica foi realizada pelo método da pipeta, utilizando uma solução de $\mathrm{NaOH} 0,1 \mathrm{~N}$ como dispersante químico, e agitaçáo mecânica em aparato de alta rotação por 10 minutos. A fraçấo argila foi separada por sedimentação, as areias, grossa e fina, por tamisação, e o silte calculado por diferença. Foi determinada a argila dispersa em água e feito o cálculo do grau de floculação, segundo metodologia da Embrapa (1997).

A densidade do solo foi obtida pelo método do anel volumétrico e a densidade de partículas pelo método do baláo volumétrico conforme metodologia da Embrapa (1997). A porosidade total $(\mathrm{Pt})$ foi calculada a partir dos dados obtidos das densidades do solo (Ds) e de partícula (Dp), empregandose a seguinte expressão: $\mathrm{Pt}=100(1-\mathrm{Ds} / \mathrm{Dp})$.

A condutividade hidráulica saturada dos solos foi determinada em amostras deformadas (TFSA), utilizando-se cílindro plástico com $23 \mathrm{~cm}$ de altura e $2,5 \mathrm{~cm}$ de diâmetro, com permeâmetro de carga constante. A condutividade hidráulica foi calculada conforme a lei de Darcy e expressa em $\mathrm{cm} \mathrm{h}^{-1}$, conforme Embrapa (1997).

Cálcio, magnésio e alumínio trocáveis foram extraídos com $\mathrm{KCl} 1 \mathrm{~mol} \mathrm{~L}^{-1}$; o potássio, sódio e fósforo disponível, foram extraídos com solução de Mehlich-1; e a acidez potencial $(\mathrm{H}+\mathrm{Al})$ foi extraída com soluçáo tamponada a $\mathrm{pH}$ 7,0 de acetato de cálcio, utilizando-se metodologia proposta pela Embrapa (1997). Com base nos resultados das análises químicas foram calculadas a soma de bases (SB), a capacidade de troca catiônica (CTC), a saturação por bases (V\%) e alumínio. $\mathrm{O}$ pH foi determinado potenciometricamente utilizando-se relação 1:2,5 de solo: em água e $\mathrm{KCl}$ (Embrapa 1997).

O carbono orgânico total foi determinado pelo método de oxidação por via úmida, com aquecimento externo (Yoemans e Bremner 1988).

$\mathrm{Na}$ terra fina seca ao ar (TFSA) foram determinados os óxidos do ataque sulfúrico $\left(\mathrm{Al}_{2} \mathrm{O}_{3} \mathrm{e} \mathrm{Fe}_{2} \mathrm{O}_{3}\right)$, após digestão com $\mathrm{H}_{2} \mathrm{SO}_{4} 1: 1$, seguido de dissolução alcalina para $\mathrm{SiO}_{2}$, segundo método descrito por Embrapa (1979).

As formas cristalinas de ferro $\left(\mathrm{Fe}_{\mathrm{d}}\right)$ foram extraídas com ditionito-citrato-bicarbonato de sódio (DCB), segundo metodologia de Mehra e Jackson (1960). Para extraçáo dos óxidos mal cristalizados de ferro $\left(\mathrm{Fe}_{\mathrm{o}}\right)$, alumínio $\left(\mathrm{Al}_{\mathrm{o}}\right)$ e silício $(\mathrm{Si}$ ) foi utilizado o oxalato ácido de amônio (Camargo et al. 1986).

Após a separação das frações areia, silte e argila foi realizada a identificação por difratometria de raios-X (DRX). Os difratogramas foram obtidos empregando-se difratômetro Shimadzu, operando a uma tensão de $40 \mathrm{kv}$, com corrente de $20 \mathrm{~mA}$, radiação de Cuk $\alpha$, com monocromador de grafite. Vale diferenciar que foi utilizada a amplitude de varredura de 5 a $70^{\circ}(2 \theta)$ e uma velocidade de registro de $3^{\circ} 2 \theta$ min ${ }^{-1}$ para as fraçóes areia e silte, e amplitude de 3 a $70^{\circ}(2 \theta)$ e mesma velocidade para a argila, todos pelo método do pó. Em seguida foram realizados tratamentos específicos para a fração argila, amostras saturadas com $\mathrm{KCl}$ (temperatura ambiente e aquecidas a $550^{\circ} \mathrm{C}$ ) e saturadas com $\mathrm{MgCl}_{2}$ com posterior solvatação com glicerol. A amplitude de varredura foi de 3 a $35^{\circ}(2 \theta)$ e a velocidade de registro de $2^{\circ} 2 \theta \mathrm{min}^{-1}$.

\section{RESULTADOS E DISCUSSÃO}

\section{Caracterização dos pedoambientes}

Com base na vegetação e no relevo a paisagem foi subdividida em quatro unidades pedoambientais: campo alto, situado no platô rebaixado da paisagem, com ocorrência de gramíneas dos gêneros Andropogon e Paspalum e árvores retorcidas e espaçadas, como Curatella americana L. e Eupatorium sp ; campo baixo, formado por depressôes inundadas durante as chuvas e secas na estiagem, com predominância de gramíneas e ciperáceas, dos gêneros Andropogon e Paspalum; zona de ecótono, caracteriza-se por um ambiente de tensáo ecológica entre os dois ecossistemas (campos/floresta), com presença de gramíneas e espécies de pequeno e médio porte, tais como Sclerolobium paniculatum, Himatanthus sucunba e Mabea caudata; eflorestas, localizadas nas áreas mais elevadas e de melhor drenagem da paisagem, funcionando como um divisor de água, e exibindo uma fisiografia de floresta densa estabelecida, com presença de espécies como Euterpe precatoria, Vismia guianensis, Orbignya speciosa, Oenocarpus bacaba e Mabea subsessilis (Figura 1).

Estas fisionomias assemelham-se às encontradas por Braun e Ramos (1959) que afirmaram que a regiāo apresenta o aspecto fitofisionômico de floresta - campo. O relevo por sua vez, apresenta-se próximo ao tipo "tabuleiro", com um pequeno desnível e pequenas depressóes. Essas terras mais altas constituem os divisores topográficos de água entre rios da regiáo. O desnível entre essas zonas mais elevadas e o vale dos igarapés, é da ordem de 15 a 29 metros, ocorrendo, entretanto, de maneira abrupta, com vales encaixados.

De maneira geral, os solos que ocorrem nesta topossequência têm relação direta com a variação do relevo, que condiciona a drenagem e o nível do lençol freático. O grau de desenvolvimento dos perfis, a presença e a profundidade dos mosqueados e horizontes plínticos e glei, corroboram esta afirmaçâo. Estas características assemelham-se às observadas por Vidotto et al. (2007) em estudos de dinâmica do ecótono floresta-campo no sul do estado do Amazonas.

\section{Classificação dos Solos}

Nos pedoambientes de campo baixo e zona de ecótono os horizontes gleizados $(\mathrm{Cg})$, ocorrem a partir de $27 \mathrm{e} 90 \mathrm{~cm}$, respectivamente, para Gleissolo Háplico (GXalt) e Cambissolo 
Háplico (CXalg). Para os pedoambientes de campo alto e floresta a presença do horizonte plíntico (Cf) ocorre a partir dos 90 e $130 \mathrm{~cm}$ de profundidade, respectivamente, para o Cambissolo Háplico (CXalf) e o Argissolo Vermelho (PValf). Este fato evidencia o papel determinante da água nessas variaçôes, pois a presença do horizonte glei reflete a presença do lençol freático e condiçôes anaeróbicas durante a maior parte do ano, coincidindo com as posições mais baixas da topossequência.

Por outro lado, os pedoambientes de campo alto e floresta, de posição mais alta, apresentam o horizonte plíntico, também oriundo da presença de lençol freático, mas que alterna frequentemente com condiçôes de oxidação. Neste caso, o efeito temporário do excesso de umidade, seguido de um período de aeração, favorece a segregação e concentração dos óxidos de ferro na forma de mosqueados ou coloração variegada, com cores vermelhas (Anjos et al. 2007).

Os solos dos diversos pedoambientes foram assim classificados: campo alto - Cambissolo Háplico Alítico plíntico, textura média, A moderado, com seqüência de horizontes A-BA-Bi-BC-Cf; campo baixo - Gleissolo Háplico Alítico típico, textura argilosa, A moderado, com seqüência: $\mathrm{A}_{1}-\mathrm{A}_{2}-\mathrm{Cg}_{1}-\mathrm{Cg}_{2}$; zona de ecótono - Cambissolo Háplico Alítico gleissólico, textura siltosa, A moderado com seqüência: A-BABi-BC-Cg; e floresta - Argissolo Vermelho Alítico plíntico, textura média (leve)/média, A moderado, com seqüência de horizontes: A-AB-BA-Bt $\mathrm{t}_{1}-\mathrm{Bt}_{2}-\mathrm{BCf}$ (Tabela 1).

Tabela 1 - Atributos morfológicos dos solos de uma topossequência de transição campos/floresta na região de Humaitá, AM.

\begin{tabular}{|c|c|c|c|c|c|c|c|}
\hline \multirow{2}{*}{ Horiz. } & \multirow{2}{*}{$\begin{array}{l}\text { Prof. } \\
\text { (cm) }\end{array}$} & \multicolumn{2}{|c|}{ Cor Munsell (úmida) } & \multirow{2}{*}{ Textura } & \multirow{2}{*}{${ }^{2}$ Estrutura } & \multirow{2}{*}{${ }^{3}$ Consistência } & \multirow{2}{*}{${ }^{4}$ Transição } \\
\hline & & Matriz & ${ }^{1}$ Mosqueado & & & & \\
\hline \multicolumn{8}{|c|}{ Campo Alto - Cambissolo Háplico Alítico plíntico } \\
\hline A & $0-14$ & $7,5 Y R 4 / 6$ & & franca & maciça coesa & ext.dr., fir., plás. e peg. & cla. e pla. \\
\hline BA & $14-30$ & 2,5YR 5/8 & & franco-siltosa & mod., mpeq. a peq., bl.sub. & mdr., fir., plás. e peg. & gra. e pla. \\
\hline $\mathrm{Bi}$ & $30-66$ & $2,5 Y R 4 / 8$ & & franca & fo., mpeq., bl.ang. a bl.sub. & mdr., fir., mplás. e mpeg. & cla. e pla. \\
\hline $\mathrm{BC}$ & $66-90$ & 2,5 YR 4/8 & $\begin{array}{l}\text { 10YR 6/3, po., peq. a } \\
\text { méd. e pro. }\end{array}$ & franca & mod., peq. a méd., bl.ang. & mdr., fir., plás. e peg. & gra. e pla. \\
\hline $\mathrm{Cf}$ & $90-160$ & 2,5 YR 4/8 & 2,5YR 5/8 e 10YR 5/8 & franca & fr. a mod., méd., bl.ang. & ext.dr., mfir., plás. e peg. & \\
\hline \multicolumn{8}{|c|}{ Campo Baixo - Gleissolo Háplico Alítico típico } \\
\hline$A_{1}$ & $0-15$ & 10YR 3/1 & & franco-argilo-siltosa & maciça a moderadamente coesa & mdr., fri., plás. e peg. & gra. e ond. \\
\hline $\mathrm{A}_{2}$ & $15-27$ & 10YR 4/1 & 10YR 5/6, po., peq. e dif. & franco-argilo-siltosa & fr. peq. a méd., bl.sub. & mdr., fri., mplás. e mpeg. & cla. e ond. \\
\hline $\mathrm{Cg}_{1}$ & $27-80$ & 10YR 5/1 & 2,5YR 4/6, po., peq. e pro. & franco-argilo-siltosa & fo. gr. a mgr., prism. e bl.sub. & ext.dr., ext.fir., mplás. e mpeg. & dif. e pla. \\
\hline $\mathrm{Cg}_{2}$ & $80-115$ & 10YR 5/1 & 2,5YR 4/6, co. peq. e pro. & argilo-siltosa & fo. mgr., prism. e bl.sub. & ext.dr., ext.fir., mplás. e mpeg. & \\
\hline \multicolumn{8}{|c|}{ Zona de Ecótono - Cambissolo Háplico Alítico gleissólico } \\
\hline A & $0-15$ & 10YR 5/4 & & franco-siltosa & fr., peq. a méd., bl.sub e gran. & mdr., fir., mplás e mpeg. & gra. e pla. \\
\hline BA & $15-32$ & 10YR 5/4 & & franco-siltosa & fr., peq. a méd., bl.sub. & ext.dr., fir., mplás e mpeg. & gra. e pla. \\
\hline $\mathrm{Bi}$ & $32-50$ & 10YR 5/4 & & franco-argilo-siltosa & fr., méd. a gr., prism. e bl.sub. & ext.dr., mfir., mplás e mpeg. & cla. e pla. \\
\hline $\mathrm{BC}$ & $50-90$ & 10YR 6/3 & 2,5YR 4/8, co., peq. e pro. & franco-argilo-siltosa & fr., peq. a méd., bl.sub. & ext.dr., mfir., mplás e mpeg. & dif. e pla. \\
\hline $\mathrm{Cg}$ & $90-140$ & 10YR 6/3 & 2,5YR 4/8, co., gr. e pro. & franco-argilo-siltosa & fr., peq. a méd., bl.sub. & ext.dr., mfir., mplás e mpeg. & \\
\hline \multicolumn{8}{|c|}{ Floresta - Argissolo Vermelho Alítico plíntico } \\
\hline$A_{1}$ & $0-15$ & 10YR 4/4 & & franco-siltosa & $\begin{array}{l}\text { mod., peq. a méd., gran. e } \\
\text { bl.sub. }\end{array}$ & mdr., fri., plás e peg. & gra. e pla. \\
\hline$A B$ & $15-34$ & 7,5YR 5/6 & & franco-siltosa & $\begin{array}{l}\text { mod., mpeq. a peq., bl.ang. } \\
\text { e bl.sub. }\end{array}$ & mdr., fir., mplás e peg. & gra. e pla. \\
\hline BA & $34-67$ & 7,5YR 5/6 & & franca & $\begin{array}{l}\text { mod., peq. a méd., bl.ang. e } \\
\text { bl.sub. }\end{array}$ & mdr., fir., mplás e peg. & gra. e pla. \\
\hline $\mathrm{Bt}_{1}$ & $67-100$ & 2,5YR 4/8 & & franco-argilosa & $\begin{array}{l}\text { mod., mpeq. a méd., bl.ang. } \\
\text { e bl.sub. }\end{array}$ & mdr., fir., mplás e mpeg. & gra. e pla. \\
\hline $\mathrm{Bt}_{2}$ & $\begin{array}{l}100- \\
130\end{array}$ & $2,5 Y R 5 / 8$ & $\begin{array}{l}\text { 10YR 6/8, co., peq. a } \\
\text { méd. e pro. }\end{array}$ & franco-argilosa & mod., mpeq. a méd., bl.ang. & ext.dr., fir., mplás e mpeg & gra. e pla. \\
\hline BCf & $\begin{array}{l}130- \\
200\end{array}$ & 10YR 5/8 & $\begin{array}{l}2,5 Y R \text { T/8, co., peq. a } \\
\text { méd. e pro. }\end{array}$ & franco-argilosa & mod., mpeq. a méd., bl.ang. & ext.dr., mfir., mplás e mpeg & \\
\hline
\end{tabular}

${ }^{1}$ co: comum; ab: abundante; pro: proeminente; dif: difuso; po: pouco; dis: distinto. ${ }^{2}$ fr.: fraca, mod.: moderada; fo.:forte; peq.: pequena, mpeq.: muito pequena; méd.: média: gr.: grande; mgr.: muito grande; gran.: granular; bl. ang.: blocos angulares; bl. sub.: blocos subangulares, prism.:prismática. ${ }^{3}$ so.: solto; mac.: macio; lig.dr:: ligeiramente duro; dr.: duro; mdr.: muito duro; ext.dr.: extremamente duro; mfri.: muito friável; fri.: friável; fir.: firme; mfir.: muito firme; ext.fir.: extremamente firme; nplás.: nẫo plástico; lig.plás.: ligeiramente plástico; plás.: plástico; mplás.: muito plástico; npeg.: não pegajoso; lig.peg.: ligeiramente pegajoso; peg.: pegajoso; mpeg.:muito pegajoso. ${ }^{4}$ cla.: clara; pla.: plana; gra.:gradual; ond.: ondulada; dif.: difusa; abr.:abrupta. 
Em relaçáo à taxonomia dos solos, observou-se a formaçáo de três grupos segundo o SiBCS: o primeiro formado pela ordem dos Argissolos (P4), o segundo pela ordem dos Cambissolos (P1 e P3) e o terceiro pela ordem dos Gleissolos (P2). O Argissolo ocorre no pedoambiente de Floresta, mais alto e conseqüentemente mais bem drenado, contribuindo para um maior desenvolvimento pedogenético, apresentando horizonte plíntico a $130 \mathrm{~cm}$.

Os Cambissolos ocorrem em posiçóes mais baixas do relevo e foram enquadrados em uma mesma subordem, apesar de apresentarem diferenças de posição no relevo. O perfil do pedoambiente de campo alto tem posiçáo mais elevada e foi classificado como Cambissolo Háplico Alítico plíntico, apresentando horizonte plíntico a $90 \mathrm{~cm}$ de profundidade. $\mathrm{O}$ solo da zona de ecótono tem posição mais rebaixada, é menos evoluído e foi classificado como Cambissolo Háplico Alítico gleissólico, com pior condição de drenagem, comprovada pela presença de um horizonte glei a $90 \mathrm{~cm}$ de profundidade.

Na posiçáo mais baixa e de restritas condiçóes de drenagem o solo do campo baixo foi classificado como Gleissolo, com cores de redução a partir dos $27 \mathrm{~cm}$. O excesso de água retarda o desenvolvimento pedogenético, predominando o processo de gleização.

Os solos de todos os pedoambientes estudados apresentaram caráter alítico, que influenciou a classificação no terceiro nível, devido aos altos teores de alumínio trocável e argila de atividade alta. Esta característica está relacionada com o material de origem aluvial, proveniente dos afluentes do rio Madeira, que trazem sedimentos com estas características.

\section{Atributos Morfológicos do Solo}

Observou-se uma relação entre a cor do solo e as condiçóes de drenagem dos pedoambientes, pois os solos das posiçôes mais altas e de melhor drenagem (campo alto e floresta) apresentaram matiz 2,5YR, predominando cores vermelhas. Para a zona de ecótono, mais baixa e com maior restrição de drenagem, foi observada matiz 10YR, com cores amareladas a acinzentadas e, no pedoambiente de campo baixo, observou-se matiz 10YR, com dominância de cores acinzentadas. Nestes dois últimos pedoambientes predominaram solos com cores de cromas mais baixos indicando assim, as influências do lençol freático elevado e condiçóes redutoras, interferindo no comportamento dos solos (hidromorfismo).

Em relação às classes texturais, verificou-se que os solos dos pedoambientes de campo alto e floresta apresentaram textura semelhante, sendo textura franca no Cambissolo Háplico Alítico plíntico do campo alto, e textura franco-argilosa no Argissolo Vermelho Alítico plíntico da floresta. Para os pedoambientes de campo baixo e zona de ecótono, posiçóes mais baixas e de menor desenvolvimento pedogenético a classe textural dominante foi franco-argilo-siltosa, tanto para o Gleissolo Háplico Alítico típico, como para o Cambissolo Háplico Alítico gleissólico (Tabela 1).

A estrutura do solo exibiu grau de desenvolvimento moderado para os solos do campo alto e floresta, com estrutura muito pequena a pequena em blocos angulares e subangulares. Para os solos da zona de ecótono e campo baixo, respectivamente, a estrutura apresentou grau de desenvolvimento moderado a forte para todos os horizontes, exceçáo feita ao horizonte $A_{1}$ do Gleissolo que apresentou arranjamento maciço moderadamente coeso. O tipo de estrutura foi predominantemente em blocos angulares e subangulares, para os Argissolos e Cambissolos e prismática no Gleissolo (Tabela 1).

A consistência do solo quando seco variou de muito dura a extremante dura, apresentando-se friável nos horizontes superficiais e firme a extremamente firme nos demais. A consistência molhada oscilou entre plástica e muito plástica e pegajosa e muito pegajosa (Tabela 1).

Verificou-se presença de concreçôes ferruginosas nos pedoambientes de campo alto e floresta, possivelmente decorrentes da alternância de umedecimento e secagem, conforme destacam Martins et al. (2006a), Lima et al. (2006) e Fritsch et al. (2007), em solos na regiâo amazônica.

\section{Atributos Físicos do Solo}

Verificou-se que os conteúdos de argila foram bastante semelhantes em todos os pedoambientes, apresentando valores mais elevados no Gleissolo da parte mais baixa da paisagem. Em contrapartida, os teores de areia foram mais baixos nos pedoambientes de campo baixo e zona de ecótono quando comparados aos pedoambientes de campo alto e floresta (Tabela 2).

A fração silte é dominante em todos os pedoambientes, fato justificável pela natureza aluvial dos sedimentos que constituem o material de origem (Brasil 1978). Comparando os diversos pedoambientes, observou-se que nos pedoambientes campo baixo e zona de ecótono os teores de silte são mais elevados que nos ambientes de campo alto e floresta. Segundo Rosolen e Herpin (2008) esse comportamento se deve, principalmente, à posição rebaixada, e à ocorrência de depressóes topográficas que favorecem a deposição de sedimentos mais finos.

Em relaçáo à argila natural, observou-se que os maiores teores são encontrados nos horizontes superficiais, devido aos elevados teores de matéria orgânica da superfície, em combinação com a mineralogia caulinítica. Segundo Alleoni e Camargo (1994) um dos fatores que concorre para um valor mais elevado de argila dispersa em água (ADA) na camada superficial é o maior teor de matéria orgânica, uma das principais fontes de carga negativa dos solos. Esses mesmos autores relatam que em solos com elevado teores de alumínio, como é o caso, pode haver dispersão de caulinita pela ação de 
Tabela 2 - Atributos físicos dos solos de uma topossequência de transição Campos/Floresta na região de Humaitá, AM.

\begin{tabular}{|c|c|c|c|c|c|c|c|c|c|c|c|c|}
\hline \multirow[t]{2}{*}{ Horiz. } & Prof. & Areia Grossa & Areia Fina & Silte & Argila & $\begin{array}{l}\text { Argila } \\
\text { Natural }\end{array}$ & G. F. & $S / A$ & Ds & $\mathrm{Dp}$ & Pt & CHSS \\
\hline & $\mathrm{cm}$ & & \multicolumn{3}{|c|}{$\mathrm{g} \mathrm{kg}^{-1}$} & \multicolumn{3}{|c|}{$\%$} & \multicolumn{2}{|c|}{$\mathrm{g} \mathrm{cm}^{-3}$} & $\%$ & $\mathrm{~cm}^{\mathrm{h}-1}$ \\
\hline \multicolumn{13}{|c|}{ Campo Alto - Cambissolo Háplico Alítico plíntico } \\
\hline A & $0-14$ & 14 & 352 & 450 & 183 & 46 & 74 & 2,4 & 1,3 & 2,6 & 50 & 1,0 \\
\hline BA & $14-30$ & 8 & 259 & 528 & 203 & 11 & 94 & 2,5 & 1,4 & 2,5 & 43 & 1,0 \\
\hline $\mathrm{Bi}$ & $30-66$ & 38 & 221 & 411 & 328 & 20 & 93 & 1,2 & 1,5 & 2,6 & 43 & 0,3 \\
\hline $\mathrm{BC}$ & $66-90$ & 11 & 316 & 410 & 262 & 17 & 93 & 1,5 & 1,5 & 2,6 & 43 & 0,1 \\
\hline Cf & $90-160$ & 15 & 357 & 381 & 244 & 32 & 86 & 1,5 & 1,5 & 2,6 & 41 & 1,0 \\
\hline \multicolumn{13}{|c|}{ Campo Baixo - Gleissolo Háplico Alítico típico } \\
\hline$A_{1}$ & $0-15$ & 3 & 36 & 631 & 329 & 45 & 86 & 1,9 & 0,8 & 2,4 & 65 & 1,9 \\
\hline $\mathrm{A}_{2}$ & $15-27$ & 5 & 42 & 632 & 319 & 29 & 90 & 1,9 & 1,1 & 2,6 & 56 & 1,6 \\
\hline $\mathrm{Cg}_{1}$ & $27-80$ & 3 & 51 & 585 & 359 & 19 & 94 & 1,6 & 1,5 & 2,7 & 44 & 0,0 \\
\hline $\mathrm{Cg}_{2}$ & $80-115$ & 3 & 39 & 540 & 416 & 10 & 97 & 1,3 & 1,6 & 2,7 & 39 & 0,0 \\
\hline \multicolumn{13}{|c|}{ Zona de Ecótono - Cambissolo Háplico Alítico gleissólico } \\
\hline A & $0-15$ & 11 & 71 & 675 & 241 & 43 & 79 & 2,8 & 1,0 & 2,6 & 59 & 1,0 \\
\hline BA & $15-32$ & 13 & 60 & 668 & 256 & 64 & 72 & 2,6 & 1,3 & 2,6 & 49 & 0,1 \\
\hline $\mathrm{Bi}$ & $32-50$ & 5 & 50 & 633 & 310 & 10 & 96 & 2,0 & 1,4 & 2,6 & 44 & 0,0 \\
\hline$B C$ & $50-90$ & 5 & 57 & 661 & 276 & 5 & 98 & 2,3 & 1,5 & 2,5 & 38 & 0,6 \\
\hline $\mathrm{Cg}$ & $90-140$ & 1 & 90 & 667 & 240 & 7 & 96 & 2,7 & 1,5 & 2,6 & 40 & 0,1 \\
\hline \multicolumn{13}{|c|}{ Floresta - Argissolo Vermelho Alítico plíntico } \\
\hline $\mathrm{A} 1$ & $0-15$ & 13 & 320 & 519 & 146 & 84 & 42 & 3,5 & 1,0 & 2,6 & 61 & 3,1 \\
\hline$A B$ & $15-34$ & 3 & 313 & 518 & 164 & 41 & 74 & 3,1 & 1,2 & 2,6 & 54 & 0,8 \\
\hline BA & $34-67$ & 2 & 284 & 498 & 213 & 10 & 95 & 2,3 & 1,3 & 2,6 & 48 & 0,6 \\
\hline $\mathrm{Bt}_{1}$ & $67-100$ & 2 & 230 & 450 & 316 & 20 & 93 & 1,4 & 1,4 & 2,6 & 45 & 0,5 \\
\hline $\mathrm{Bt}_{2}$ & $100-130$ & 2 & 223 & 438 & 335 & 9 & 97 & 1,3 & 1,4 & 2,6 & 46 & 0,4 \\
\hline $\mathrm{BCf}$ & $130-200$ & 4 & 236 & 443 & 315 & 31 & 90 & 1,4 & 1,5 & 2,6 & 43 & 0,3 \\
\hline
\end{tabular}

$\mathrm{GF}=$ grau de floculação; $\mathrm{DS}=$ densidade do solo; $\mathrm{Dp}=$ densidade de partícula; $\mathrm{Pt}=$ porosidade total; $\mathrm{CHSS}=$ condutividade hidráulica do solo saturado; $\mathrm{S} / \mathrm{A}=$ silte/argila.

ânions orgânicos produzidos pela decomposiçáo da matéria orgânica e por exsudados de raízes.

O grau de floculação (GF) refere-se à relação entre a argila naturalmente dispersa e a argila total, obtida após dispersão, esta variável comportou-se de forma contrária à argila natural, com valores mais baixos nos horizontes superficiais e aumentando em profundidade em todos os solos. Os maiores teores de matéria orgânica da superfície também contribuíram para a variação da densidade do solo que teve comportamento semelhante, com valores menores nos horizontes superficiais e aumento em profundidade, resultado comum para solos da regiâo de Humaitá, conforme destacaram Martins el al. (2006a).

A condutividade hidráulica do solo saturado apresentou valores mais elevados nos horizontes superficiais decrescendo em profundidade para todos os pedoambientes, com destaque para o pedoambiente de floresta, que apresentou valores mais altos indicando uma condiçẫo mais propicia à infiltração de água no solo. Segundo Marques et al. (2008), em estudo de uma topossequência na regiáo amazônica, as mudanças na condutividade hidráulica saturada estão mais relacionadas com alteraçôes nas propriedades físicas do solo e posiçáo no relevo, do que com a cobertura vegetal.

\section{Atributos Químicos do Solo}

Os valores de $\mathrm{pH}$ em água e $\mathrm{KCl}$ não apresentaram grandes variaçóes, situando-se entre 3,8 a 5,2 em água e 3,1 a 4,4 em $\mathrm{KCl}$ (Tabela 3). Os valores de $\Delta \mathrm{pH}$, entretanto, foram maiores nos solos dos pedoambientes de campo baixo e zona de ecótono (Tabela 3), evidenciando solos pedogeneticamente menos evoluídos, quando comparados ao campo alto e floresta.

Os maiores teores de $\mathrm{C}$ orgânico ocorreram nos horizontes superficiais, fato comum na região amazônica. Os teores de matéria orgânica são mais baixos nos solos sob campo alto e floresta e aumentam gradativamente em direção aos pedoambientes de campo baixo e zona de ecótono, influenciados pela topografia e hidromorfismo, corroborando com resultados encontrados por Rosolen e Herpin (2008) que estudaram solos na região Sul do Amazonas. 
Tabela 3 - Atributos químicos dos solos de uma topossequência de transição Campos/Floresta na região de Humaitá, AM.

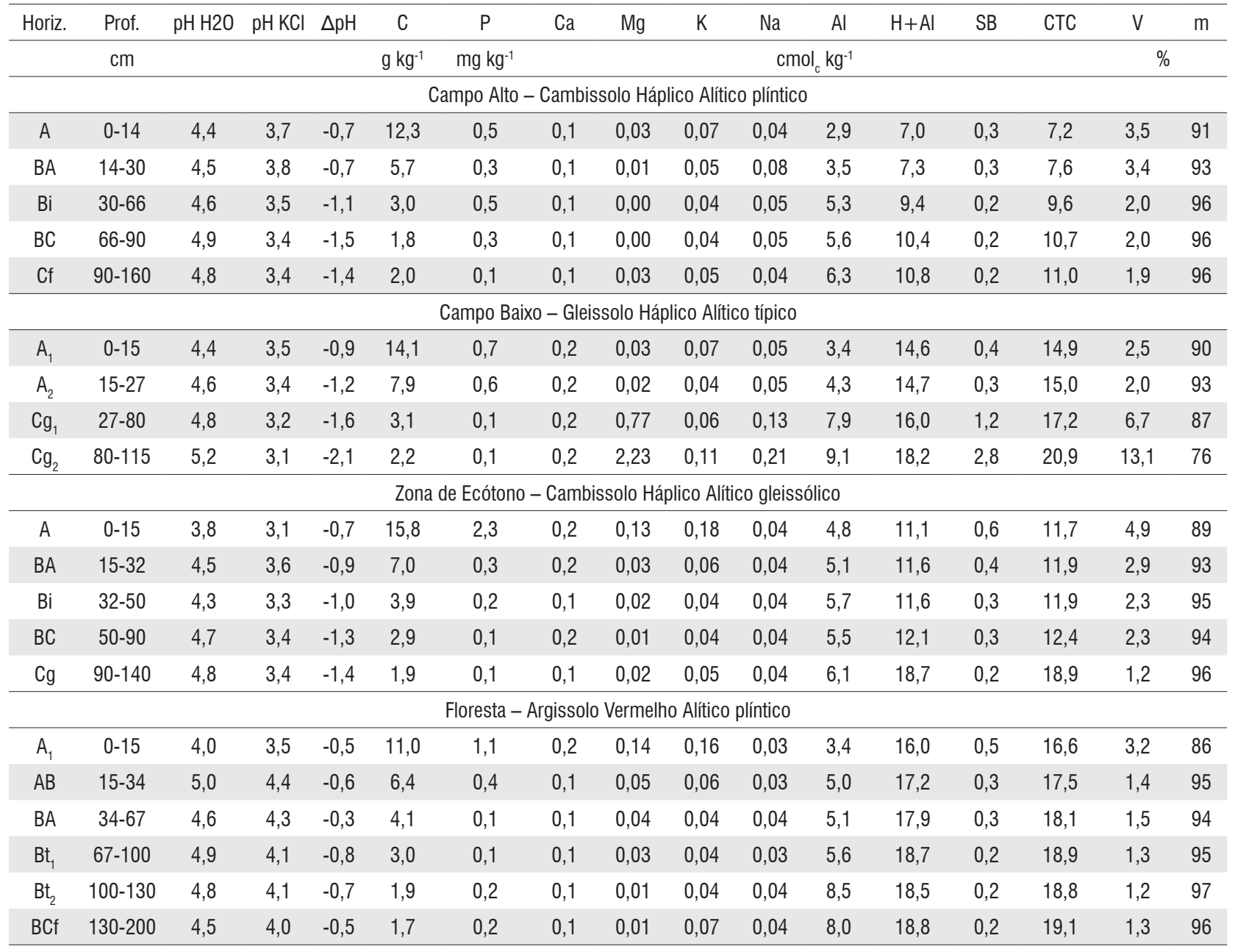

SB : soma de bases; CTC : capacidade de troca catiônica; V: saturação de bases; m: saturação por alumínio.

Os teores de P disponível apresentam comportamento similar à matéria orgânica (Tabela 3), concordando com Silva et al. (2006), que verificou que o fósforo apresenta tendência decrescente em relação à profundidade, refletindo a pouca mobilidade e a baixa solubilidade de seus compostos, sobretudo em solos de natureza ácida, com elevados teores de óxidos de ferro e alumínio.

Os solos da topossequência são dessaturados e as bases trocáveis (cálcio, magnésio, sódio e potássio) apresentaram valores baixos em todos os pedoambientes. Em oposiçáo, os teores de $\mathrm{Al}^{3+}$ trocável, excetuando alguns horizontes superficiais, apresentaram valores $>4 \mathrm{cmol} \mathrm{kg}^{-1}$. (Tabela 3 ). Este fato está relacionado com a natureza dos sedimentos (ricos em minerais 2:1 aluminosos) que formaram o material de origem, conforme destaca Martins et al. (2006b) em estudo realizado na região de Humaitá, AM.

Os valores da acidez potencial $\left(\mathrm{H}^{+}+\mathrm{Al}^{3+}\right)$ são elevados (Tabela 3), com comportamento crescente em profundidade em todos os pedoambientes. Entre os pedoambientes, verificou-se que a floresta apresentou os maiores resultados, provavelmente, em conseqüência da maior lixiviação promovida pelo intenso regime hídrico associado às melhores condiçóes de drenagem (Campos et al. 2010b).

Os solos apresentaram-se dessaturados, com soma de bases (SB) e saturaçáo por bases $(\mathrm{V})$ muito baixas em todos os pedoambientes. A área de floresta, entretanto, foi a que apresentou os valores menos expressivos (Tabela 3). Por outro lado, a capacidade de troca de cátions (CTC) apresentou valores mais elevados, provavelmente, em consequência da mineralogia dos solos. Em contrapartida, os valores de saturação por alumínio (m\%) foram acima de $90 \%$ para o pedoambiente de campo alto, entre 86 e $97 \%$ para os pedoambientes das zonas de ecótono e floresta, e entre 76 e $93 \%$, no campo baixo, valores coerentes com os encontrados por Martins et al. (2006a) que estudou os solos em uma transição campos/mata na região de Humaitá. AM. 
Os teores dos óxidos do ataque sulfúrico $\left(\mathrm{SiO}_{2}, \mathrm{Al}_{2} \mathrm{O}_{3} \mathrm{e}\right.$ $\mathrm{Fe}_{2} \mathrm{O}_{3}$ ) mostraram comportamento crescente em profundidade para todos os pedoambientes (Tabela 4). Os menores teores de $\mathrm{SiO}_{2}$, entretanto, foram encontrados no pedoambiente de floresta, evidenciando assim um ambiente mais intemperizado em relação aos demais. Para os teores $\mathrm{de}_{2} \mathrm{Al}_{2} \mathrm{O}_{3}$ constatou-se que o pedoambiente de campo baixo apresentou valores mais elevados em relação aos pedoambientes de campo alto, zona de ecótono e floresta (Tabela 4). De acordo com Rosolen e Herpin (2008) em ambientes constantemente saturados por água, ocorre a mobilização, redistribuição e exportação do ferro, sílica e outros elementos químicos.

Em relação aos teores de $\mathrm{Fe}_{2} \mathrm{O}_{3}$, foram observados valores diferentes em relação aos pedoambientes, com resultados mais expressivos nos pedoambientes campo alto e floresta do que nos demais pedoambientes (Tabela 4). As condiçôes de maior hidromorfismo podem provocar reduçáo nos teores dos óxidos de ferro. Além disso, de acordo com Schaefer e Dalrymple (1996) os elevados teores de matéria orgânica e a pobreza em ferro do material de origem podem contribuir para estes resultados.

Em relação aos óxidos extraídos por ditionito-citratobicarbonato (DCB), verificou-se que seus valores distribuíramse de forma crescente com a profundidade do solo (Tabela 4). Os teores dos óxidos de ferro cristalinos variaram nos pedoambientes, sendo o campo alto (CXalf) o pedoambiente com maiores teores, com o horizonte $\mathrm{Bi}$ apresentando os valores mais elevados, coincidindo com o início da ocorrência das concreçôes ferruginosas.

Os teores de ferro e alumínio extraídos com oxalato ácido de amônio (OAA) foram maiores nos horizontes subsuperficiais, e crescentes com a profundidade. Estes resultados são explicados pela ligação com a matéria orgânica, que desfavorece a cristalizaçáo dos óxidos, e corroboram os resultados encontrados por Campos et al. (2010a) em estudo sobre a gênese dos solos na região Sul do Amazonas.

Verificou-se também que os teores de alumínio extraídos com oxalato ácido de amônio (OAA) foram elevados em todos os pedoambientes, com maiores valores no campo baixo (Tabela 4), possivelmente, devido à saturação com água. Os óxidos de silício também extraídos com oxalato ácido de amônio (OAA) comportaram-se de maneira mais pronunciada nos ambientes de campo baixo e zona de ecótono, em comparação com os ambientes de floresta e campo alto, provavelmente também em função do regime hídrico conforme destacam Fu et al. (2004).

Para Kämpf e Schwertmann (1983) os valores da relação $\mathrm{Fe}_{o x} / \mathrm{Fe}_{\mathrm{d}}\left(\mathrm{Fe}_{\mathrm{ox}}=\right.$ extraído por oxalato ácido de amônio e $\mathrm{Fe}_{\mathrm{d}}$ = extraído por ditionito-citrato-bicarbonato) são indicadores do grau de cristalinidade dos óxidos de ferro. Nesse sentido

Tabela 4 - Teores dos óxidos do ataque sulfúrico $\left(\mathrm{SiO}_{2}, \mathrm{Fe}_{2} \mathrm{O}_{3}, \mathrm{Al}_{2} \mathrm{O}_{3}\right)$, óxidos livre extraídos com ditionito-citrato-bicarbonato $\left(\mathrm{SiO}_{2}, \mathrm{Fe}_{2} \mathrm{O}_{3}, \mathrm{Al}_{2} \mathrm{O}_{3}\right)$ e formas amorfas extraídos com oxalato acido de amônio $\left(\mathrm{SiO}_{2}, \mathrm{Fe}_{2} \mathrm{O}_{3}, \mathrm{Al}_{2} \mathrm{O}_{3}\right)$ e relações entre eles, nos diversos pedoambientes em uma topossequência de transição Campos/Floresta na região de Humaitá, AM

\begin{tabular}{|c|c|c|c|c|c|c|c|c|c|c|c|c|c|c|c|c|}
\hline \multirow{3}{*}{ Pedoambientes } & \multirow{3}{*}{ Horiz } & \multicolumn{3}{|c|}{$\begin{array}{l}\text { Óxidos do Ataque } \\
\text { Sulfúrico }\end{array}$} & \multirow[t]{2}{*}{ Ki } & \multirow[t]{2}{*}{$\mathrm{Kr}$} & \multicolumn{3}{|c|}{$\begin{array}{c}\text { Ditionito Citrato } \\
\text { Bicarbonato }\end{array}$} & \multicolumn{3}{|c|}{$\begin{array}{l}\text { Oxalato Ácido de } \\
\text { Amônio }\end{array}$} & \multicolumn{4}{|c|}{ Relações } \\
\hline & & $\mathrm{SiO}_{2}$ & $\mathrm{Fe}_{2} \mathrm{O}_{3}$ & $\mathrm{Al}_{2} \mathrm{O}_{3}$ & & & $\mathrm{SiO}_{2}$ & $\mathrm{Fe}_{2} \mathrm{O}_{3}$ & $\mathrm{Al}_{2} \mathrm{O}_{3}$ & $\mathrm{SiO}_{2}$ & $\mathrm{Fe}_{2} \mathrm{O}_{3}$ & $\mathrm{Al}_{2} \mathrm{O}_{3}$ & $\mathrm{Fe}_{\alpha x} / \mathrm{Fe}_{\mathrm{d}}$ & $\mathrm{Al}_{\alpha x} / \mathrm{Al}_{d}$ & $\mathrm{Si}_{\alpha x} / \mathrm{Si}_{d}$ & $\mathrm{Fe}_{\mathrm{d}} / \mathrm{Fe}_{\mathrm{s}}$ \\
\hline & & \multicolumn{5}{|c|}{-----dag kg-1------- } & \multicolumn{10}{|c|}{ - } \\
\hline \multicolumn{17}{|c|}{ Cambissolo Háplico Alítico plíntico } \\
\hline \multirow{3}{*}{ Campo Alto } & A & 3,7 & 8,1 & 8,1 & 0,78 & 0,48 & 2,60 & 5,00 & 4,70 & 0,60 & 0,30 & 3,30 & 0,06 & 0,70 & 0,23 & 0,62 \\
\hline & BA & 4,6 & 10,7 & 9,4 & 0,83 & 0,48 & 3,70 & 5,80 & 5,30 & 0,80 & 0,20 & 4,00 & 0,03 & 0,75 & 0,22 & 0,54 \\
\hline & $\mathrm{Bi}$ & 6,1 & 18,1 & 12,2 & 0,85 & 0,44 & 4,20 & 12,80 & 7,50 & 1,40 & 0,10 & 4,50 & 0,01 & 0,60 & 0,33 & 0,71 \\
\hline \multicolumn{17}{|c|}{ Gleissolo Háplico Alítico típico } \\
\hline \multirow{3}{*}{ Campo Baixo } & $A_{1}$ & 9,1 & 7,2 & 15,1 & 1,10 & 0,85 & 4,20 & 5,20 & 6,70 & 2,20 & 1,00 & 5,70 & 0,19 & 0,85 & 0,52 & 0,72 \\
\hline & $\mathrm{A}_{2}$ & 8,4 & 4,7 & 17,1 & 0,84 & 0,71 & 4,30 & 3,70 & 7,60 & 2,30 & 0,30 & 7,00 & 0,08 & 0,92 & 0,53 & 0,79 \\
\hline & $\mathrm{Cg}_{1}$ & 8,9 & 10,1 & 17,5 & 0,86 & 0,63 & 5,70 & 9,20 & 9,80 & 2,20 & 0,40 & 6,80 & 0,04 & 0,69 & 0,39 & 0,91 \\
\hline \multicolumn{17}{|c|}{ Cambissolo Háplico Alítico gleissólico } \\
\hline \multirow{3}{*}{ Zona de Ecótono } & A & 6,0 & 8,1 & 10,0 & 1,02 & 0,67 & 2,20 & 5,70 & 4,10 & 2,10 & 1,10 & 2,90 & 0,19 & 0,71 & 0,95 & 0,70 \\
\hline & BA & 5,1 & 9,1 & 12,0 & 0,72 & 0,49 & 2,60 & 6,10 & 5,90 & 2,20 & 0,90 & 2,70 & 0,15 & 0,46 & 0,85 & 0,67 \\
\hline & $\mathrm{Bi}$ & 9,3 & 9,3 & 14,0 & 1,13 & 0,79 & 3,10 & 7,30 & 6,20 & 2,20 & 0,60 & 2,80 & 0,08 & 0,45 & 0,71 & 0,79 \\
\hline \multicolumn{17}{|c|}{ Argissolo Vermelho Alítico plíntico } \\
\hline \multirow{3}{*}{ Floresta } & $A_{1}$ & 3,3 & 6,4 & 4,6 & 1,22 & 0,65 & 1,80 & 4,20 & 2,30 & 1,20 & 0,50 & 2,10 & 0,12 & 0,91 & 0,67 & 0,66 \\
\hline & BA & 4,8 & 8,1 & 10,1 & 0,81 & 0,53 & 1,20 & 5,80 & 5,10 & 1,10 & 0,30 & 3,00 & 0,05 & 0,59 & 0,92 & 0,72 \\
\hline & $\mathrm{Bt}_{1}$ & 5,1 & 13,1 & 13,1 & 0,66 & 0,40 & 2,90 & 9,20 & 5,80 & 2,01 & 0,30 & 3,20 & 0,03 & 0,55 & 0,69 & 0,70 \\
\hline
\end{tabular}

Ki: relação \% $\mathrm{SiO}_{2} \times 1,7 / \% \mathrm{Al}_{2} \mathrm{O}_{3} ; \mathrm{Kr}_{2} \% \mathrm{SiO}_{2} \times 1,7 /\left(\% \mathrm{Al}_{2} \mathrm{O}_{3}+\% \mathrm{Fe}_{2} \mathrm{O}_{3}\right.$ × 0,64); $\mathrm{Fe}_{\text {ox }}$ : $\mathrm{Fe}_{2} \mathrm{O}_{3}$ extraído pelo oxalato ácido de amônio; $\mathrm{Si}_{\mathrm{o}}$ : $\mathrm{SiO}_{2}$ extraído pelo oxalato ácido de amônio; $\mathrm{Al}_{\alpha}: \mathrm{Al}_{2} \mathrm{O}_{3}$ extraído pelo oxalato ácido de amônio; $\mathrm{Fed}: \mathrm{Fe}_{2} \mathrm{O}_{3}$ extraído pelo ditionito citrato bicarbonato; $\mathrm{Sid}_{\mathrm{S}} \mathrm{SiO}_{2}$ extraído pelo ditionito citrato bicarbonato; $\mathrm{Ald}$ : $\mathrm{Al}_{2} \mathrm{O}_{3}$ extraído pelo ditionito citrato bicarbonato; $\mathrm{Fe}_{\mathrm{s}}: \mathrm{Fe}_{2} \mathrm{O}_{3}$ extraído com ácido sulfúrico. 
verificou-se que estes resultados tendem a decrescer com a profundidade, indicando a maior cristalinidade nos horizontes subsuperficiais. Segundo Demattê et al. (1994) a medida que os óxidos vão ficando menos cristalinos, eles são mais facilmente removidos do solo e transportados para as partes mais baixas.

Os valores da relação $\mathrm{Fe}_{\mathrm{d}} / \mathrm{Fe}_{\mathrm{s}},\left(\mathrm{Fe}_{\mathrm{d}}=\right.$ extraído por ditionitocitrato-bicarbonato e $\mathrm{Fe}_{\mathrm{s}}=$ extraído pelo ataque sulfúrico) distribuíram-se com certa uniformidade, indicando que os solos de todos os pedoambientes, apresentam o mesmo estádio de óxido-redução dos ambientes, o que pode ser atribuído à natureza do material de origem e às próprias características do pedoambiente (Tabela 4).

\section{Atributos Mineralógicos do Solo}

A composição mineralógica dos solos, em todas as frações analisadas, revelou uma riqueza em minerais silicatados, com pequenas variaçóes em toda a topossequência estudada. A fração areia nos diferentes pedoambientes comportouse de maneira bastante uniforme em todos os horizontes diagnósticos estudados, sendo composta exclusivamente por quartzo (Tabela 5).

Em relação à mineralogia da fraçáo silte observou-se que, com exceção do pedoambiente de campo baixo, todos os demais apresentaram nos horizontes diagnósticos subsuperficiais ( $\mathrm{Bi}$ e $\mathrm{Bt}_{1}$ ) presença da muscovita (Tabela 5). Esta fração ainda apresentou outros componentes mineralógicos, como feldspato, anatásio e quartzo em todos os horizontes dos pedoambientes estudados. Por outro lado, a ilmenita foi observada apenas nos pedoambientes de campo alto e floresta, possivelmente devido à melhor drenagem, uma vez que em condiçôes de hidromorfismo o Fe é reduzido conforme destacam Marques et al. (2002) em estudos na Amazônia Ocidental.
A fração argila apresentou composição mineralógica semelhante em todos os perfis, com caulinita, mica (ilita) e anátasio. Foi observada a presença de pirofilita nos horizontes de todos os solos, exceto no Bi do campo alto e no $\mathrm{Cg}_{1}$ do campo baixo. De acordo com Lips e Duivenvoorden (1996), que estudou solos da Amazônia Colombiana, este mineral é bastante encontrado em rochas e saprolitos dos Andes, porém, normalmente ocorre em quantidades muito reduzidas em solos. Esta constatação é um indicativo de que estes solos podem ter recebidos contribuiçôes de materiais andinos. Apesar destas áreas não receberem atualmente contribuições do Rio Madeira, segundo Brasil (1978), como estes solos são formados a partir de sedimentos Aluviais Antigos oriundos do Holoceno e provenientes de sedimentaçáo fluvial ou sedimentaçâo lacustrina, é possivel que em algum momento os sedimentos andinos adentraram estas áreas, o que explicaria a presença desse mineral.

Foi observada a presença de mica/ilita em todos os solos, independentemente dos pedoambientes (Tabela 5). Segundo Brasil (1978) este argilomineral foi provavelmente formado a partir do intemperismo dos sedimentos micáceos contidos nas frações mais grosseiras do solo, já que a fração silte de todos eles apresenta muscovita em sua constituição (Tabela 5).

De acordo com Kämpf e Curi (2000) a vermiculita pode ser originada a partir das micas, fato que pode explicar a presença de vermiculita nos solos dos pedoambientes de campo alto, campo baixo e floresta (Tabela 5). Com relação às esmectitas, verificou-se que ocorreram em todos os pedoambientes, estando coerente com os resultados encontrados por Lima $e t$ al. (2006), que estudou mineralogia e química de solos em uma topossequência da Bacia Sedimentar Alto do Solimóes, AM. A possível explicação para a presença na esmectita, está associada com a drenagem restrita e o suprimento de soluçóes

Tabela 5 - Composição mineralógica das frações areia, silte e argila dos horizontes diagnósticos superficiais e subsuperficiais nos diversos pedoambientes em uma topossequência de transição Campos/Floresta na região de Humaitá, AM.

\begin{tabular}{|c|c|c|c|c|}
\hline Pedoambientes & Horizonte & Areia & Silte & Argila \\
\hline \multicolumn{5}{|c|}{ Cambissolo Háplico Alítico plíntico } \\
\hline \multirow{2}{*}{ Campo Alto } & A & Qz & Qz, e Im & Vm, M/II, Pf, Ct, Gt e An \\
\hline & $\mathrm{Bi}$ & Qz & Ms, Q, An e Fd & $\mathrm{Em}, \mathrm{I}, \mathrm{Vm}, \mathrm{M} / \mathrm{II}, \mathrm{Ct}$, Gt e An \\
\hline \multicolumn{5}{|c|}{ Gleissolo Háplico Alítico típico } \\
\hline \multirow{2}{*}{ Campo Baixo } & A & Qz & $\mathrm{Qz}, \mathrm{An}, \mathrm{Gb}$ e Fd & Vm, M/II, Pf, Ct, e An \\
\hline & $\mathrm{Cg}_{1}$ & Qz & $\mathrm{Qz}, \mathrm{An}, \mathrm{Gb}$ e Fd & $\mathrm{Em}, \mathrm{M} / \mathrm{II}, \mathrm{K}$ e An \\
\hline \multicolumn{5}{|c|}{ Cambissolo Háplico Alítico gleissólico } \\
\hline \multirow{2}{*}{ Zona de Ecótono } & A & Qz & Qz, An e Fd & Em, M/II, Pf, Ct, Gt e An \\
\hline & $\mathrm{Bi}$ & Qz & Ms, Qz, An e Fd & Em, M/ll, Pf, Ct e An \\
\hline \multicolumn{5}{|c|}{ Argissolo Vermelho Alítico plíntico } \\
\hline \multirow{2}{*}{ Floresta } & $A_{1}$ & Qz & Qz, An e Fd & Em, M/II, Pf, Ct, Gt e An \\
\hline & $\mathrm{Bt}_{1}$ & Qz & Ms, Qz, Im, An e Fd & Vm, M/II, Pf, Ct e An \\
\hline
\end{tabular}

$\mathrm{Ms}=$ muoscovita; $\mathrm{Ct}=$ caulinita; $\mathrm{Gb}=$ gibbsita; $\mathrm{Qz}=$ quartzo; $\mathrm{An}=$ anatásio; $\mathrm{Fd}=$ feldspatos; $\mathrm{Im}=\| \mathrm{lmenita}, \mathrm{I}=$ interestratificados, $\mathrm{Pf}=$ pirofilita, $\mathrm{Vm}=$ vermiculita, $\mathrm{E}=$ esmectita, M/ll = mica(ilita), Gt = goethita. 
ricas em $\mathrm{Si}, \mathrm{Al}, \mathrm{Mg}$ e Fe, que condicionam a sua formação e preservaçáo (Kämpf e Curi 2000). Neste caso específico, possivelmente, o tipo de esmectita encontrado seria a beidelita, já que pode ser originada do intemperismo das micas.

\section{CONCLUSÕES}

A variação dos solos na topossequência tem relação direta com a variação do relevo, que condiciona a drenagem e o nível do lençol freático, favorecendo o aparecimento horizontes glei ou plínticos;

A fraçáo silte foi dominante em todos os pedoambientes estudado, com destaque para os pedoambientes de campo baixo e zona de ecótono, partes rebaixadas do relevo;

Foi constatada presença de pirofilita na fração argila de todos os solos estudados, o que é um indicativo de que estes solos receberam contribuiçóes de materiais mineralogicamente mais jovens, com possível influencia andina.

\section{BIBLIOGRAFIA CITADA}

Alleoni, L.R.F.; Camargo, O.A. 1994. Atributos físicos de Latossolos Ácricos do norte paulista. Scientia Agricola, 51: 321-326.

Anjos, L.H.C.; Pereira, M.G.; Pérez, D.V.; Ramos, D.P. 2007. Caracterizaçáo e classificação de plintossolos no município de Pinheiro-MA. Revista Brasileira de Ciência do Solo, 31: 10351044.

Botrel, R. T.; Oliveira Filho, A. T.; Rodrigues, L. A.; Curi, N. 2002. Influência do solo e topografia sobre as variaçôes da composiçáo florística e estrutura da comunidade arbóreo-arbustiva de uma floresta estacional semidecidual em Ingaí, MG. Revista Brasileira de Botânica, 25: 195-213.

Brasil. 1978. Ministério das Minas e Energia. Projeto Radambrasil Folha SB. 20, Purus. Rio de Janeiro. 561 pp.

Braun, E.H.G.; Ramos, J.R.A. 1959. Estudo agroecológico dos campos Puciarí-Humaitá (Estado do Amazonas e Território Federal de Rondônia). Revista Brasileira de Geografia, 21: 443497.

Camargo, O.A.; Moniz, A.C.; Jorge, J.A.; Valadares, J.M.A.S. 1986. Métodos de análise química, mineralógica e física de solos do IAC. Campinas, Instituto Agronômico de Campinas, (Boletim Técnico, 106). 94 pp.

Campos, M.C.C.; Marques Júnior, J.; Pereira, G.T.; Montanari, R.; Camargo, L.A. 2007. Relaçôes solo-paisagem em uma litosseqüência arenito-basalto na regiáo de Pereira Barreto, SP. Revista Brasileira Ciência do Solo, 31: 519-529.

Campos, M.C.C.; Ribeiro, M.R.; Souza Júnior, V.S.; Ribeiro Filho, M.R.; Costa, E.U.C. 2010a. Segmentos de vertente e atributos do solo de uma toposseqüência na regiáo de Manicoré, AM. Revista Ciência Agronômica, 41: 501-510.

Campos, M.C.C.; Ribeiro, M.R.; Souza Júnior, V.S.; Ribeiro Filho, M.R.; Oliveira, I.A. 2010 b. Interferências dos pedoambientes nos atributos do solo em uma topossequência de transição Campos/Floresta. Revista Ciência Agronômica, 41: 527-535.
Demattê, J.A.M.; Aloisi, R.R.; Dematte, J.L.I. 1994. Seqüência Latossolo Amarelo - Podzólico Amarelo - Areias Quartzosas sob material da formação barreiras na região de Tucuruí, estado do Pará. Scientia Agricola, 51: 345-356.

El-Ghani, M.M.A.; Amer, W. 2003. Soil-vegetation relationships in a coastal desert plain of southern Sinai, Egypt. Journal Arid Environmental, 55: 607-628.

Embrapa. 1979. Serviço Nacional de Levantamento e Conservação de Solos. Manual de métodos análise de solo. Rio de Janeiro. 247 pp.

Embrapa. 1997. Centro Nacional de Pesquisa de Solos. Manual de métodos de análise de solo. Rio de Janeiro. $212 \mathrm{pp}$.

Embrapa. 2006. Centro Nacional de Pesquisa de Solos. Sistema Brasileiro de Classificação de Solos. Brasília, 2006. 354 pp.

Freitas, H.A.; Pessenda, L.C.R; Aravena, R.; Gouveia, S.E.M.; Ribeiro, A.S.; Boulet, R. 2002. Florestas X Savanas no passado na Amazônia. Ciência Hoje, 32: 40-46.

Fritsch, E.; Herbillon, A.J.; Nascimento, N.R.; Grimaldi, M.; Melfi, A.J. 2007. From Plinthic Acrisols to Plinthosols and Gleysols: iron and groundwater dynamics in the tertiary sediments of the upper Amazon basin. European Journal Soil Science, 58: 989-1006.

Fu, B.J.; Liu, S.L.; Ma, K.M.; Zhu, Y.G. 2004. Relationships between soil characteristics, topography and plant diversity in a heterogeneous deciduous broad-leaved forest near Beijing, China. Plant Soil, 261: 47-54.

Jafari,M.; Zare Chahouki; M.A.; Tavili, A.; Azarnivand, H. 2003. Soil-Vegetation Relationships in Hoz-e-Soltan Region of Qom Province, Iran. Pakistan Journal Nutrition, 2: 329-334.

Kämpf, N.; Curi, N. 2000. Óxidos de ferro: indicadores de atributos de ambientes pedogênicos e geoquimicos,p.107-138. In: Novais, R.F. De; Alvarez V., V.H.; Schaefer, C.E.G.R. (Ed.) Tópicos em Ciência do Solo, v. I. Viçosa. Sociedade Brasileira de Ciência do Solo.

Kämpf, N.; Schwertmann, U. 1983. Relaçōes entre óxidos de ferro e a cor de solos cauliníticos do Rio Grande do Sul. Revista Brasileira de Ciência do Solo, 7: 27-31.

Lima, H.N.; Mello, J.W.V.; Schaefer, C.E.G.R.; Ker, J.C.; Lima, A.M.N. 2006. Mineralogia e química de três solos de uma toposseqüência da Bacia Sedimentar do Alto Solimóes, Amazônia Ocidental. Revista Brasileira de Ciência do Solo, 30: 59-68.

Lips, J.M.; Duivenvoorden, J.F. 1996. Regional patterns of well drained upland soil differentiation in the middle Caquetá basin of Colombian Amazonia. Geoderma, 72: 219-257.

Marques, J.D.O., Teixeira, W.G. Reis, A.M.; Cruz Junior. O.F.; Martins, G.C. 2008. Avaliação da condutividade hidráulica do solo saturada utilizando dois métodos de laboratório numa toposseqüência com diferentes coberturas vegetais no Baixo Amazonas. Acta Amazonica, 38: 193-206.

Marques, J.J.G.S.M.; Teixeira, W.G.; Schulze, D.G.; Curi, N. 2002. Mineralogy of soils with unusually high exchangeable $\mathrm{Al}$ from the western Amazon Region. Clay Mineralogy, 37: 651-661.

Martins, A.K.E.; Schaefer, C.E.G.R.; Silva, E.; Soares, V.P.; Correa, G.R.; Mendonça, B.A.F. 2006 b. Relaçôes solo-geoambiente em 


\section{ACTA}

áreas de ocorrência de Ipucas na planície do Médio Araguaia Estado de Tocantins. Revista Árvore, 30: 297-310.

Martins, G.C.; Ferreira, M.M.; Curi, N.; Vitorino, A.C.T.; Silva, M.L.N. 2006 a. Campos nativos e matas adjacentes da regiáo de Humaitá (AM): atributos diferenciais dos solos. Ciência e Agrotecnologia, 30: 221-227.

Mehra, O.P.; Jackson, M.L. 1960. Iron oxide removal from soils and clays by a dithionite-citrate system buffered with sodium bicarbonate, p. 317-327. In: National Conference On Clays And Clays Minerals, 7., Washington, 1960. Proceedings. New York.

Rosolen, V.; Herpin, U. 2008. Expansão dos solos hidromórficos e mudanças na paisagem: um estudo de caso na região Sudeste da Amazônia Brasileira. Acta Amazonica, 38: 483-490.

Santos, R.D.; Lemos, R.C.; Santos, H.G.; Ker, J.C.; Anjos, L.H. 2005. Manual de descrição e coleta de solos no campo. 5.ed. Viçosa. Sociedade Brasileira de Ciência do Solo. 100 pp.
Schaefer, C.E.R.G.; Dalrymple, J.B. 1996. Pedogenesis and relict properties of soil with columnar structure from Roraima, north Amazonia. Geoderma, 71:1-17.

Silva, G.E.; Silva Júnior, M.L.; Melo, V.S. 2006. Efeitos de diferentes usos da terra sobre as características químicas de um Latossolo Amarelo do Estado do Pará. Acta Amazonica, 36: 151-158.

Vidotto, E.; Pessenda, L. C..R.; Ribeiro, A.S.; Freitas, H.A.; Bendassolli, J.A. 2007. Dinâmica do ecótono floresta-campo no sul do estado do Amazonas no Holoceno, através de estudos isotópicos e fitossociológicos. Acta Amazonica, 37: 385-400.

Yoemans, J. C.; Bremner, J. M. 1988. A rapid and precise method for routine determination of organic carbon in soil. Communication Soil Science Plant Analysis, 19:1467-1476.

Recebido em: 07/04/2011

Aceito em: 28/11/2011 
